\title{
A CATALOGUE AND A CLASSIFICATION OF SURFACE CYCLONES FOR THE WESTERN MEDITERRANEAN
}

\author{
J. Campins, A. Genovés, A. Jansà, J.A. Guijarro \\ Centro Meteorológico en Illes Balears. Instituto Nacional de Meteorología \\ Palma de Mallorca, Spain. \\ C.Ramis \\ Dep. de Física. Universitat de les Illes Balears \\ Palma de Mallorca, Spain.
}

\begin{abstract}
The Mediterranean Sea is a region that presents a high frequency of cyclones. Many of them are lee depressions and so mesoscale and weak, but others are strong and cover a wide area. In this study some characteristics of surface cyclones in the Western Mediterranean are presented. First a database was built from hand analyses of sea level pressure from 1992 to 1995. Next a similar database was obtained from the LAM-INM objective analyses of the $1000 \mathrm{hPa}$ geopotential field. Results show an important increase in the number of cyclones when a mesoscale analysis is carried out. Most of the Western Mediterranean cyclones are mesoscale and weak, and they are not uniformly distributed in space and in time. On one hand, there are some areas with a high concentration of cyclones. The location of some of them, close to the main mountain ranges, suggests their possible orographic origin. On the other, in some areas the cyclones are present during the whole year, but in other areas are seasonally distributed. Finally a study of typologies of the cyclones was conducted by using the cluster analysis technique. The classification was performed from the intensity of the cyclones and the shape of the sea level pressure around the centre. Results are similar from both databases and so the existence of seven typologies have been identified.
\end{abstract}

KEY WORDS: Western Mediterranean, Cyclones, Cluster Analysis

Corresponding author address: Joan Campins

Centro Meteorológico en Illes Balears, Instituto Nacional de Meteorología

Muelle de Poniente s/n, E-07071, Palma de Mallorca, Spain

E-mail: Campins.pma@inm.es 


\section{Introduction}

The Mediterranean Sea lies between $30^{\circ}$ and $46^{\circ} \mathrm{N}$ and between $6^{\circ} \mathrm{W}$ and $36^{\circ} \mathrm{E}$. It can be divided into two main basins (separated by Sicily): the Western and the Eastern basins. The Western Mediterranean basin (Figure 1) is surrounded by high mountain ranges (tops from 1500 to 4500 metres); to the north by the Pyrenees and the Alps, to the west by the Iberian Peninsula with a complex orography, to the south by the Atlas (from the Haut Atlas in Morocco to the Massif de l' Aures in Algeria) and to the east by the Apennine mountains and the Dinaric Alps. These ranges lay close to the sea and are separated by narrow gaps.

A consequence of the topographical shape of the Mediterranean is the frequent generation of lee depressions. In general, the interaction of the air-flow with a mountain barrier produces many effects: windward blocking, deviation of the flow, lee wave generation, lee warming, etc... (Bougeault et al., 1990). The global effect is the loosing of air-flow momentum, measured by the mountain drag. The mesoscale manifestation of the mountain drag is a dipolar pressure structure, with high pressure in the windward and low pressure in the lee of the range (Bessemoulin et al., 1993).

From a macroscale (general circulation) point of view, due to its latitudinal position, the Mediterranean region is affected by both the Polar-Front Jet and the Subtropical Jet. Besides, the Mediterranean Sea separates two continental air masses (the Euro-Assiatic and the African), which implies the generation of baroclinic frontal zones. As it is well-known, these two factors, the presence of the Jet and a baroclinic zone, play an important role in the extratropical cyclogenesis (Reiter, 1975)

As a direct result from the aforementioned characteristics, the Mediterranean is a region that presents a high frequency of cyclonic centres. Many of them exhibit mesoscale features and weak intensity (Genovés and Jansà, 1989; Radinovic, 1978) but some of them are strong and cover a wide area (Radinovic, 1987; Alpert et al., 1990). Even only considering macroscale cyclones, the Mediterranean region is one of the most cyclogenetic region in the world (Petterssen, 1956; Radinovic, 1987). It can be stated that the large number of cyclones and cyclogenesis in the Western Mediterranean is one of the main features of the meteorology in that region.

Large scale deep cyclones may be directly related to disturbed weather (strong wind and/or heavy rain). But also some small, weak and shallow surface depressions may have an indirect influence in locating and triggering heavy rain (Jansà et al., 1996 and 1999) or in the generation of certain local winds (Campins et al., 1995). This is the foundation of the practical interest of a study oriented to obtain a better knowledge of those events. It seems to be necessary to improve the understanding of the characteristics of the surface cyclones and their preferred areas of appearance, not only deep cyclones, but also weak and shallow depressions.

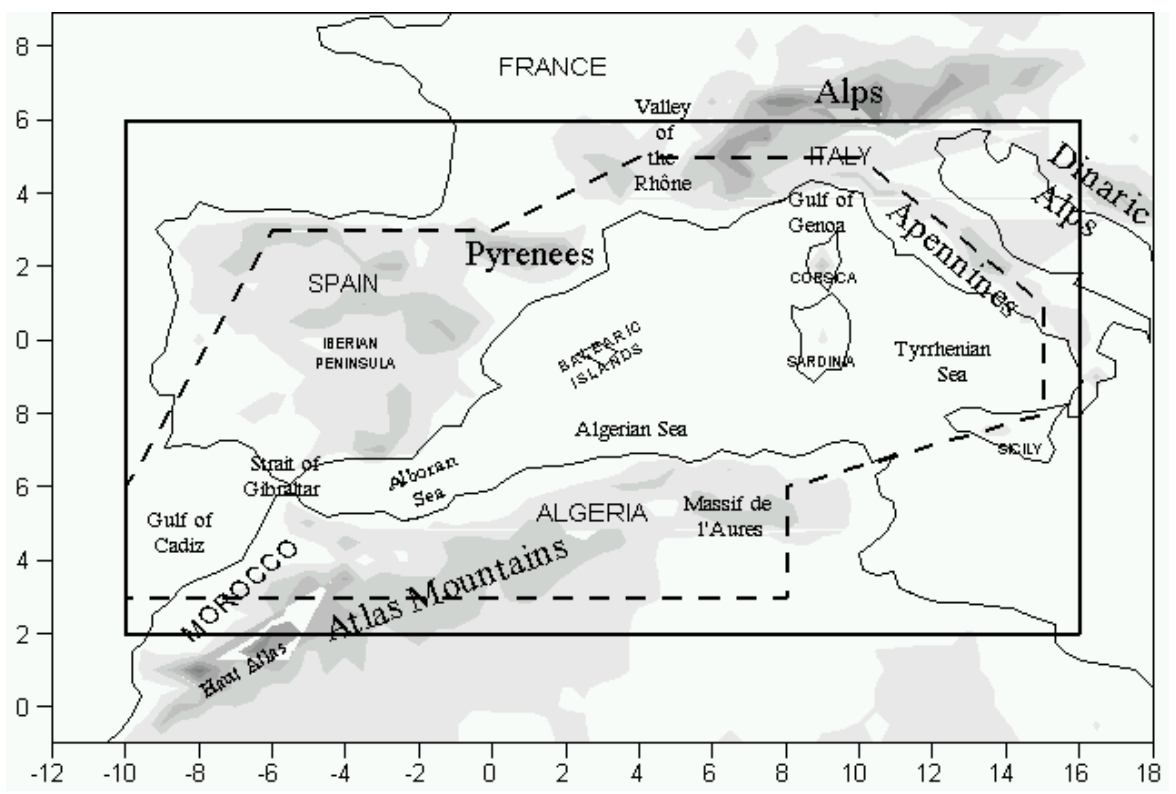

Figure 1: Western Mediterranean orography (grey scale each $500 \mathrm{~m}$ ) and study areas of the subjective (dash line) and the objective (full line) cyclone databases. 
To do that, a catalogue and a classification of the Western Mediterranean cyclones were performed. First, a catalogue of cyclones for a four-year database, which was obtained from hand-made sea level pressure analyses, was carried out. After that, a classification of that database in certain typologies by a cluster analysis method was performed. In order to validate the results an objective catalogue from the LAM-INM (Limited Area Model of the Instituto Nacional de Meteorologia of Spain) analysis data (for the same period and area) and a classification based on it, by using the same method, was compared with the first one. The present paper is organised as follows. In Section 2, a review of previous cyclone catalogues for the Western Mediterranean, as well as their most important results, are presented. In Section 3, the subjective catalogue, as well as the spatial and seasonal distributions of the Western Mediterranean cyclones obtained from it, are described. The cluster analysis method and the results on Western Mediterranean cyclone classification are shown in Section 4. In Section 5 the catalogue and the classification of the objective database are compared with the subjective one. Finally, Section 6 contains the conclusions and further remarks.

\section{Previous cyclone catalogues for the Western Mediterranean}

Cyclone and cyclogenesis climatologies have been a continuous subject of interest in the Mediterranean meteorology. The wide variety of aspects (cyclone, cyclogenesis or both), methodologies (subjective and objective), study areas (from the whole Mediterranean to some specific regions), scales (large, synoptic and mesoscale), time periods (from one to forty years) and time intervals (from 24 to 3 hours) make very difficult a comparative study of them. Even so, and as it will be seen later, the analysis of the different climatologies produces some interesting results.

The first study is included in the general work done by Petterssen (1956). Petterssen obtained the cyclone and cyclogenesis frequencies over the Northern Hemisphere. It was a large scale analysis over a forty-year period. The frequencies were presented in grid areas of $100,000 \mathrm{~km}^{2}$, and they revealed that the highest concentration of cyclogenesis in Northern Hemisphere, in winter, is the Mediterranean, in the grid square that includes the gulf of Genoa. Radinovic and Lalic (1959) presented a climatology of cyclogenesis for the Western Mediterranean. It was performed over a ten-year series of sea level pressure charts (every 6 hours). The isobar contour interval was $5 \mathrm{hPa}$. The cyclone selection criteria was based on the presence of a low pressure centre with at least one closed isobar in the study area. This was a synoptic scale climatology and the results were presented in $5^{\circ} x 5^{\circ}$ latitude-longitude squares. As well as in the study of Petterssen, the Western Mediterranean in general and the Gulf of Genoa in particular were revealed as important cyclogenetic regions. Another synoptic scale climatology was performed by Reiter (1975). He used a seven- year database of sea level pressure charts in the Mediterranean (6 hourly). The selection criteria excluded the thermal lows. The Gulf of Genoa was again the area with highest concentration of cyclones, but other regions, as the Gulf of Lyon, the Balearic Sea, North Africa and the Algerian Sea, presented secondary maxima in relation to the number of cyclones.

All the aforementioned climatologies were performed with a large or synoptic point of view. The first attempt to carry out a mesoscale cyclone climatology was performed by Radinovic (1978), and it was concerned with the Western Mediterranean (around the Alpine mountain range) and for a one-year period (1975). The cyclone selection criteria was the same as the used in 1959, but with a $2 \mathrm{hPa}$ contour interval. The analysis of sea level pressure charts was carried out 3 hourly and the results were presented in $1^{o} x 1^{\circ}$ latitude-longitude squares. Besides results from a one-year period can not be considered as a climatology, it is important to note a significant increase in the number of cyclones (as regards the large or synoptic scale cyclone climatologies). The absolute maximum remained in the Gulf of Genoa, but other zones had an important cyclone concentration.

Radinovic (1978) pointed out the possible orographic (due to the high frequency of cyclones close to the mountain ranges, especially the Alps) and thermal (due to the heating of the sea or land) character of many low pressure centres. Moreover, many of them were stationary and short-living (less than 24 hours). Following the ideas of Radinovic, Genovés and Jansà (1989) performed a catalogue of cyclones for the Western Mediterranean (excluding the Alpine area but including the Iberian Peninsula). The selection criteria of cyclones was the same as the used by Radinovic (1978), and it was applied to the sea level pressure charts, 12 hourly, over 1987. They considered not only the low pressure centres (enclosed within a $2 \mathrm{hPa}$ contour interval) but also the opened ones, with a high value of positive geostrophic vorticity. The results again pointed out to an increase of the number of cyclones when a mesoscale analysis is carried out. It is interesting to underline the high number of cyclones detected in the south of the Pyrenees, mainland Spain, the Alboran Sea and the western border of the Algerian Sea.

All of the mentioned studies were based on hand-made sea level pressure charts, generally coming from daily 
operational analysis. Thus, the detection of low centres was enterely subjective. The first climatology on the activity in the whole Mediterranean performed with an objective method was carried out by Alpert et al. (1990). In this work, the analysis outputs of the ECMWF numerical model at 00 and 12 GMT for a five- year period were used. The objective method looked for cyclones in the geopotential field at $1000 \mathrm{hPa}$. The gridlength of the analysis was $2.5^{\circ} \times 2.5^{\circ}$ latitude-longitude. The results were presented in $250 \times 250 \mathrm{~km}^{2}$ squares, and so with a synoptic scale point of view. Concerning the Western Mediterranean, the results show again a maximum in the Gulf of Genoa during the whole year. However, it is interesting to point out other maxima for some periods: the South of Italy from January to July, Sahara from April to October and the north of Algeria in July (the Iberian Peninsula was not included into the study area).

\section{A subjective catalogue of mesoscale cyclones for the Western Mediter- ranean. Spatial and seasonal distributions}

Following the methodologies discussed in Radinovic (1978) and in Genovés and Jansà (1989), since December 1992 to November 1995, the occurrence of cyclones in the Western Mediterranean basin was archived at the Meteorological Centre of the Balearic Islands. The database was built from operational hand-made analyses of the sea level pressure charts at 00 and 12 GMT, using a $2 \mathrm{hPa}$ contour interval. The scale of the map was 1:5,000,000 and the area of study is shown in Figure 1. In this case not only low pressure centres inside a closed isobar were recorded, but also those open isobar centres with a high positive geostrophic vorticity value.

The use of the manual subjective analysis technique to collect the mesoscale cyclones was justified at the moment of beginning this catalogue due to the impossibility of having an objective method of mesoscale analysis that permitted the automatic detection of the great majority of Western Mediterranean cyclonic centres. However before identifying and recording the data of a cyclonic centre, the operative analyses were reanalysed. Thus, the subjectivity and urgency of the operational analyst were compensated by a reconsideration of the meteorological situation and by a different subjectivity. Nevertheless, a high subjective component was still present during the whole process.

Moreover, it can be argued the existence of some errors in detecting cyclones in the sea, given the lack of data. This error remains reduced to some mesoscale cyclones only accountable through the introduction of conceptual models. In this case the assignment error by this reason is considered small, although it exists.

Each cyclone was characterized by the date of occurrence, an assigned code, the character (open or closed isobar around the lowest pressure), the coordinates of the centre, the central and eight surrounding pressure values (at distances of 200 and $400 \mathrm{~km}$ in the N, S, E and W directions) and, finally, two calculated magnitudes, the intensity and the geostrophic vorticity of the low centre.

According to Petterssen (1956) and Radinovic and Lalic (1959), the intensity of a cyclone can be defined as the laplacian of the pressure field around the centre. Therefore it can be computed by means of a finite differences scheme. In such case the intensity of the cyclone would have the expression

$$
I=\frac{p_{1}+p_{2}+p_{3}+p_{4}-4 p_{0}}{d^{2}}
$$

being $p_{i}(i=1$ to 4$)$ the pressure values at four points placed along the principal axis (i.e., $\mathrm{E}, \mathrm{N}, \mathrm{W}$ and $\mathrm{S}$ directions, respectively) separated a distance $\mathrm{d}$ from the centre of the depression (0), and po the pressure at the centre itself (Figure 2).

In the catalogue we defined the intensity of a cyclone by the quantity

$$
I=\frac{p_{1}+p_{2}+p_{3}+p_{4}-4 p_{0}}{4}
$$

that is proportional to the laplacian of the pressure and so to the geostrophic vorticity, as the following expression shows:

$$
\zeta_{g}=\frac{1}{\rho f_{0}} \nabla^{2} p=\frac{1}{\rho f_{0}} \frac{4 I}{d^{2}}
$$


Both the intensity and the geostrophic vorticity of the cyclone for two gridlength meshes, $d=200 a n d 400 \mathrm{~km}$ (as Figure 2 shows), were stored in the catalogue.

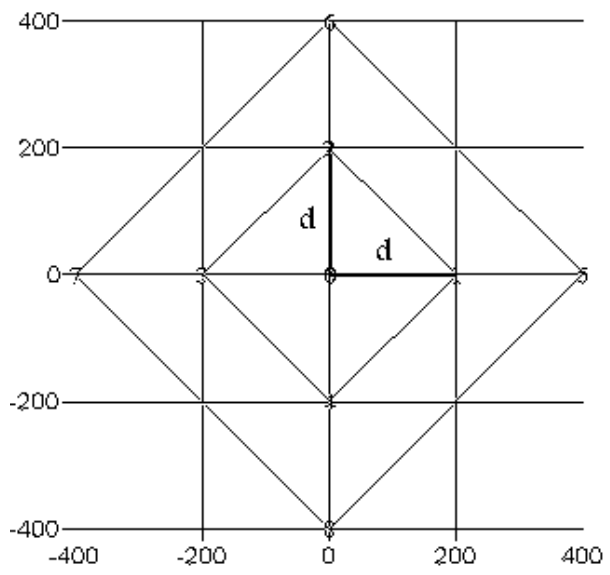

Figure 2: Grid used to calculate the variables used in the cluster analysis. The centre of the cyclone was located at point 0 . The sea level pressure values were recorded at points 0,1 to 8 . The parameter $d$ is the gridlength, and it was equal to 200 or $400 \mathrm{~km}$ (the units of the axes are in kilometres).

Due to the fact that the selection of cyclones was subjective, cyclonic centres of different scales were recorded, including some cyclones whose size was less than the shortest gridlength used $(200 \mathrm{~km})$. To avoid these undesired cyclones we ignored the cyclones with geostrophic vorticity less than $0.810^{-4} \mathrm{~s}^{-1}$ (calculated with the $200 \mathrm{~km}$ gridlength), which corresponds to a $1 \mathrm{hPa} / 200 \mathrm{~km}$ mean pressure gradient. More details about the database can be encountered in the PEMMOC (Spanish acronym for Western Mediterranean Meteorological Studies Program) Bulletin (INM 1992, 1993, 1994, 1995, 1996 and 1998).

The main features about the spatial and seasonal distributions of the collected depressions are presented in this paper. The mean number of cyclones per year is 1609 . Their spatial distribution is presented in square areas of $2^{\circ} \times 2^{\circ}$ latitude-longitude. As Figure 3 a shows, the principal maxima are located in the south of the Pyrenees and in the Gulf of Genoa. Other important areas of cyclone concentration are the Alboran Sea, the mainland Spain and the Tyrrhenian Sea.

From Figure 3a it can be observed that many of the cyclones are placed close to the main mountain ranges. It is widely accepted that in the Western Mediterranean there is a close relation between the orography and the cyclones. Moreover, as it was mentioned in Section 2, Radinovic (1978) showed this relation for an area around the Alps. In a recent study (Genovés et al., 1997) based on the same subjective database, the role of the orography was quantitatively calculated by means of an index defined as the product of the wind at $700 \mathrm{hPa}$ and the gradient of the terrain height. The results indicated that in the Western Mediterranean the cyclones in which the orography plays a decisive role are predominant.

However if the orographic origin of a great number of cyclones is assumed, it seems notorious the greater number of detected cyclones in some areas, like around the Pyrennees, in front of another mountainous zones, like the Gulf of Genoa. Probably the number of cyclones in this last maximum ought to be greater that Figure 3a shows, what would mean that there is an underestimation in the number of cyclones in the database (as results from objective catalogues indicate; see Picornell et al. 1994 and 1997). It could be due to the fact that only a part of the Alps (the western part, near Genoa) is included in the area of study. So the absolute number of detected depressions related to the Alps has to be quantitatively reduced.

The seasonal distribution for the whole database presents a maximum in summer $(29.0 \%)$ and a minimum in winter $(21.9 \%)$, while in spring and autumn the frequency of cyclones is quite similar (25.0 and $24.1 \%$ respectively). Although the difference of the seasonal frequency of cyclones is not so high, a different spatial distribution is observed in each season (Figure 4). For zones the seasonal frequency of cyclones in the Alboran Sea shows a maximum in winter and a minimum in summer, while in the mainland Spain and North Africa the seasonal distribution is the opposite, with a maximum in summer and a minimum in winter. In the south of the Pyrenees, the Gulf of Genoa and the Tyrrhenian Sea, although there exists a maximum and a minimum, the seasonal frequency is nearly uniform. In general in the cold season (winter) the low pressure centres are placed over the sea, whereas 

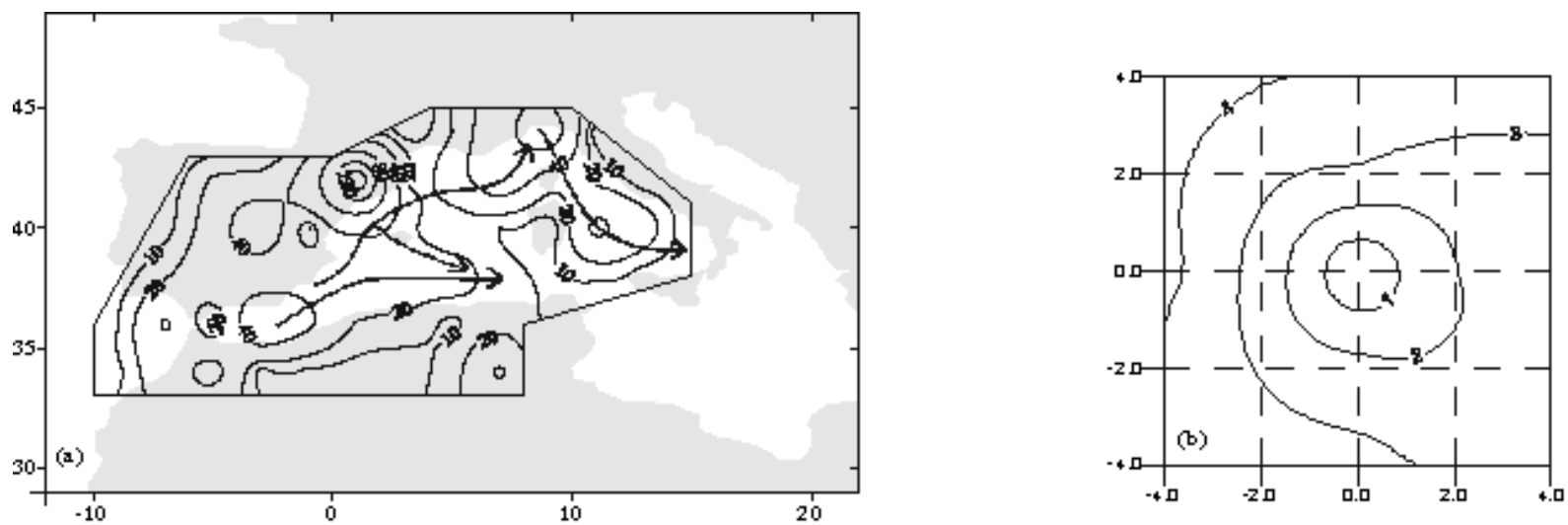

Figure 3: (a) Mean number of cyclones per year for the subjective database (1992-1995). The values were counted in $2^{\circ} \times 2^{\circ}$ squares and interpolated with the kriging method. Contours od 10, 20, 40, 80, 120 and 160 cyclones per year are shown. (b) Sea level pressure distribution (relative to the centre, $\mathrm{hPa}$ ) for the mean cyclone of the subjective database. Pressure values at points 1 to 8 interpolated with a radial method. Contour interval: $1 \mathrm{hPa}$. Grid distances in hundreds of kilometres.

in the hot season (summer) the cyclones are placed over the land, as also Radinovic (1978) found. During spring and autumn there is not a clear tendency. Therefore an important role of the radiative heating of the earth surface in the generation of the Western Mediterranean cyclones seems to be clear, especially in some areas (mainland Spain and North Africa).

In short, this catalogue confirms the south of the Pyrenees as the area with the highest frequency of small low pressure centres in the Western Mediterranean, followed by the Alboran Sea, the Algerian Sea and the Iberian Peninsula (as pointed out by Genovés and Jansà 1989). Also a prominent maximum is obtained in the Gulf of Genoa (present in all the aforementioned cyclone climatologies for the Western Mediterranean).

Although a complete study about duration and movement of cyclones has not been included in this work, comparing the results with Radinovics (1978), it can be inferred that most of the Western Mediterranean cyclones are stationary and short-living (less than 24 hours). Then the maxima of concentration of cyclones might also be the areas where cyclones appears. The elongation of the areas of maximum could give an indication of the more frequent tracks of the mobile cyclones. Therefore, from Fig. 3a some possible cyclone tracks might be inferred: (1) the important cyclogenetic region of the gulf of Genoa spans along the Tyrrhenian Sea, (2) from the maximum of the Alboran-Argelian Sea along the North- African coast or along the Iberian Peninsula coast, and finally (3) from the Catalonian-Balearic Sea to the gulf of Genoa. These tracks could be partially associated with other well-known tracks of the Western Mediterranean cyclones (Reiter, 1975; H.M.S.O., 1962).

\section{Cluster analysis}

\subsection{Method and variables}

The objective of the cluster analysis is to classify the elements, characterised by a set of variables, of a database into some groups, where the elements of the same groups are similar but different from the elements of the other groups. The algorithm used in this study was the convergent k-means, which is a variant of MacQueen's k-means algorithm (Andenberg, 1973; Gong and Richman, 1995). The measure of similarity was the euclidean distance. For this method there is not an objective way to determine the best number of clusters, and then this election is strongly subjective.

The cluster analysis was applied to the subjective cyclone database (Section 3), and two tests were performed in order to obtain the best number of clusters (k). First, we plotted the total sum of squared intra- cluster distances as a function of the number of clusters (from 2 to 10). In the convergent k-means method, for a given $\mathrm{k}$, the total sum of squared intra-cluster distances $(\mathrm{E}(\mathrm{k}))$ is a minimum, and it decreases as $\mathrm{k}$ increases. So, we chose $\mathrm{k}$ when 

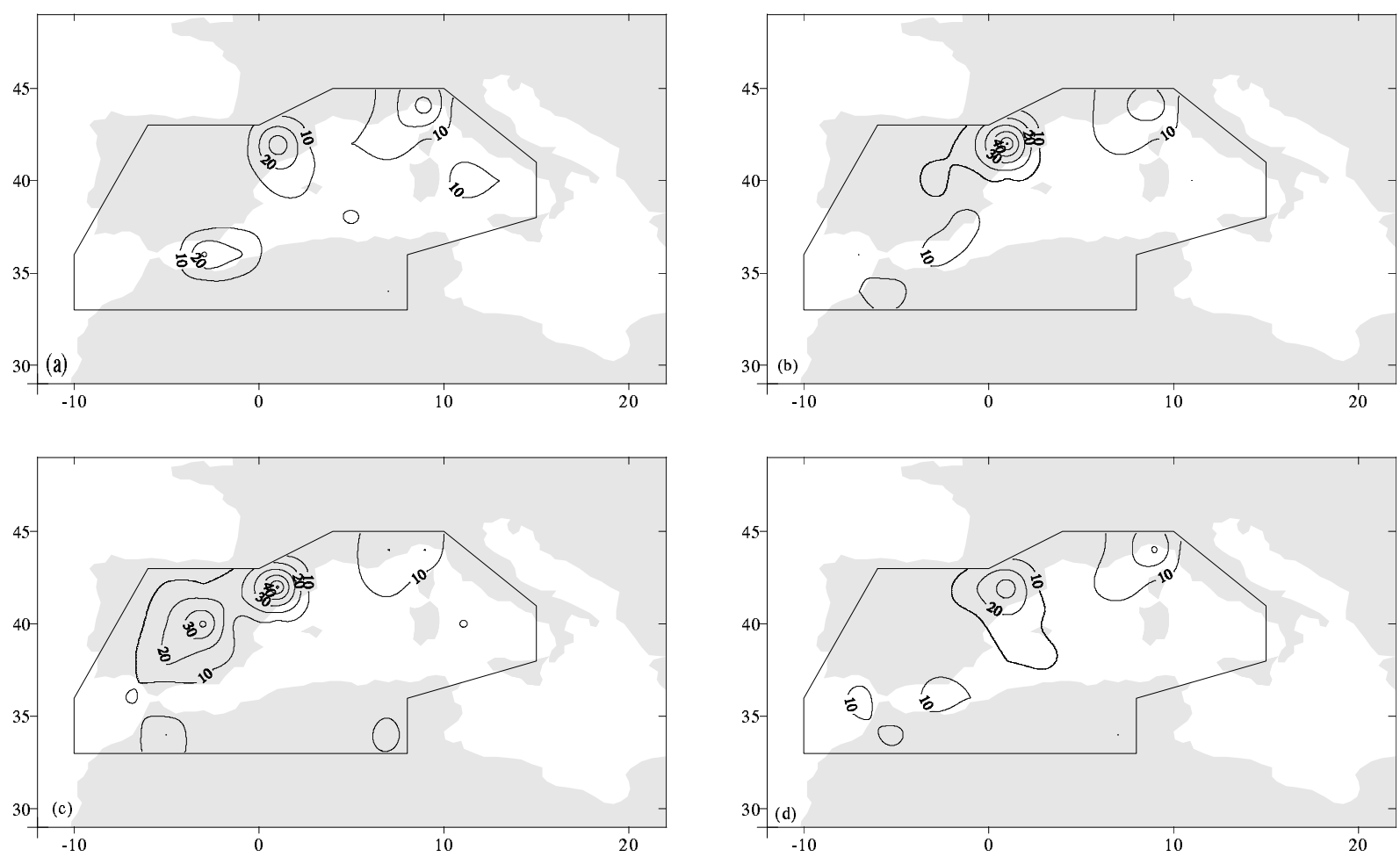

Figure 4: As Figure 3a for (a) Winter, (b) Spring, (c) Summer and (d) Autumn. Contour interval 10 cyclones per year.

the reduction of $\mathrm{E}(\mathrm{k})$ ) was not significant (for the subjective database it was achieved when $k=7$ ). And second, we compared the maximum of the inter-cluster distances versus the minimum of the intra-cluster distances. In that case the best number of clusters would be $k=4$ but for $k=7$ the minimum of the intra-cluster distance is still higher than the maximum inter-cluster distance. In order to get a higher variety of typologies, we chose 7 clusters.

The convergent k-means cluster method is also sensitive to the election of the seed-points. After some tests, the seed points were formed as the centroids of a partition of the database in 7 groups with the same number of elements.

As it has been commented, the pressure structures in the surface are closely related to the orography. Radinovic (1978) showed that the mesoscale pressure systems (high and low pressure centres) in the Western Mediterranean had a shape modelled, in many cases, by the topography. In this study we pretend to classify the Mediterranean cyclones by their intensity and shape deduced from the pressure distribution around the low pressure centre.

As measure of the intensity of the cyclone the geostrophic vorticity can be considered (see Eq. (3) in Section 3). In this case two gridlengths were used (200 and $400 \mathrm{~km}$ ). In order to characterise the shape of the pressure structure another two variables were defined: the symmetry and the eccentricity. The symmetry represents the variation of the pressure gradients around the centre and the eccentricity the difference between the mean pressure gradient along the north-south (N-S) axis and the east-west (E-W) axis. As the symmetry is calculated by means of the standard deviation of the pressure differences around the centre, then a low value indicates a nearly circular shape. The eccentricity means the difference between the pressure gradient along the N-S and E-W axes, so the stretching of the pressure shape along one of those axes. Positive values mean a bigger pressure gradient in the N-S direction than in the E-W direction, and then a stretching in the E-W axis. Negative values mean a stretching in the N-S axis and finally nearly zero values no stretching in any of both axes. As it has been commented, the shape variables as the symmetry and the eccentricity are defined as follows:

$$
\operatorname{Symmetry}(i)=\frac{s(g(i, j))}{\overline{g(i, j)}}
$$

where $s(g(i, j))$ is the standard deviation of the pressure differences at $200 \mathrm{~km}$ and $\overline{g(i, j})$, the mean of the pressure 


$$
\operatorname{Eccen}(i)=\frac{g_{N S}(i)-g_{E W}(i)}{\overline{g(i, j)}}
$$

with $g_{E W}(i)=g(i, 1)+g(i, 3), g_{N S}(i)=g(i, 2)+g(i, 4)$.

Before applying the cluster analysis the four variables (given by Eq. (3), (4) and (5)) were standardized in order to obtain nondimensional variables with zero mean and unit standard deviation.

\subsection{Results}

Before analysing the results of the cluster analysis, a description of the distribution of the four variables used in the cluster analysis is performed. In Figure 5 the mean number of cyclones per year distribution for the geostrophic vorticity (calculated with a 200 and a $400 \mathrm{~km}$ gridlengths), the symmetry and the eccentricity are shown.

The geostrophic vorticity, calculated with a $200 \mathrm{~km}$ gridlength shows an positive asymmetric distribution, with a mean $\left(2.0210^{-4} s^{-1}\right)$ greater than the median $\left(1.8910^{-4} s^{-1}\right)$. This is only partially due to the lower threshold $\left(0.810^{-4} s^{-1}\right)$, that cuts the left tail of the distribution. The minimum and the maximum values ranges from 0.80 (threshold) to $6.8010^{-4} s^{-1}$, and the standard deviation is $0.7310^{-4} s^{-1}$.

In the same way, the geostrophic vorticity, calculated with a $400 \mathrm{~km}$ gridlength exhibits a positive asymmetric shape, althought with a similar mean and median $\left(0.72\right.$ and $\left.0.6810^{-4} s^{-1}\right)$. For this variable no threshold was imposed and then negative geostrophic values can be obtained. In this case the range of values is shorter that in the previous case (the minimum is $-0.6410^{-4} s^{-1}$ and the maximum $2.8810^{-4} s^{-1}$ ) and also the standard deviation is lower $\left(0.3110^{-4} s^{-1}\right)$.
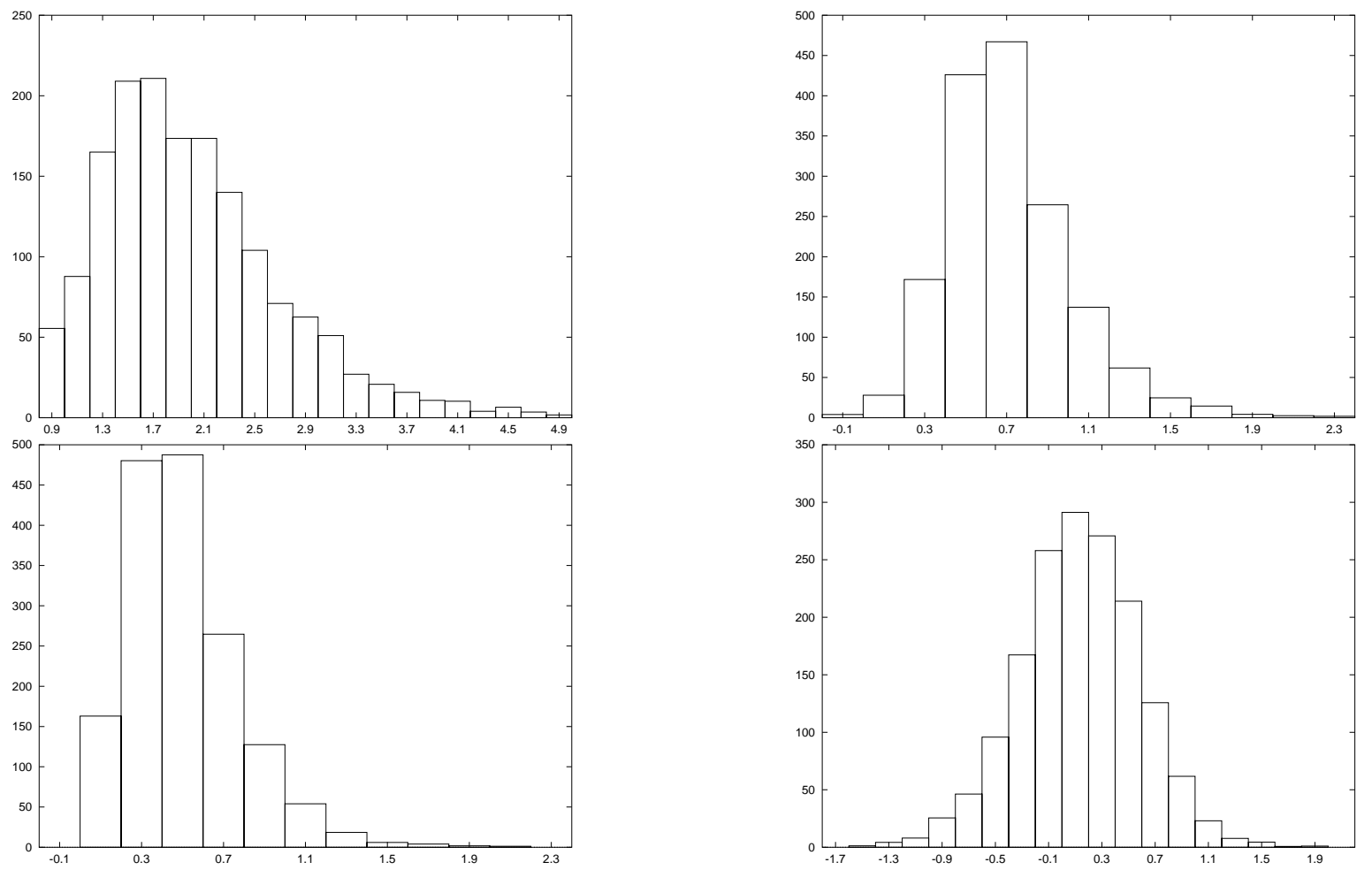

Figure 5: Frequency histogram (mean number of cyclones per year) of (a) Geostrophic vorticity calculated with a $200 \mathrm{~km}$ gridlength $\left(10^{-4} s^{-1}\right)$ (b) Geostrophic vorticity calculated with a $400 \mathrm{~km}$ gridlength $\left(10^{-4} s^{-1}\right)(c)$ Symmetry and (d) Eccentricity

Referring to the symmetry, again the distribution is positive asymmetric, with a mean equals to 0.51 and a median 
to 0.47 , that is, the most of the cyclones are not exactly symmetric. Although the symmetry values range from the minimum 0.00 value to the maximum value 2.71 , most of the values are placed around the mean. As a result, the standard deviation is small (0.28).

Finally the distribution of the eccentricity is nearly symmetric. The mean and the median are the same, 0.14 , positive, that means frequent elliptic shape, with E-W orientation of the major axis. The value range is from - 2.97 to 2.35 and the standard deviation is 0.45 .

In Figure 3b, the sea level pressure distribution for the mean cyclone in the database is presented. The pressure gradient is nearly the same in three of the four directions (around $1 \mathrm{hPa} / 100 \mathrm{~km}$ ) and weaker to the east. Its geostrophic vorticity is weak and the pressure distribution around the centre is only partially symmetric, and a little eccentric (i.e. the low pressure centre elongated in the E-W direction).

Next the characteristics of the seven typologies are described. In Table 1 the mean value of the variables for the whole database and for each one of the obtained centroids. Figures 3 and 6 show the spatial distribution and the mean pressure distribution for the whole database and for each typology.

\begin{tabular}{|c|c|c|c|c|c|c|c|c|}
\hline & Database & Type 1 & Type 2 & Type 3 & Type 4 & Type 5 & Type 6 & Type 7 \\
\hline Vort $_{2}{ }^{*}$ & 2.02 & 1.51 & 1.56 & 1.65 & 2.60 & 1.62 & 3.61 & 2.38 \\
\hline Vort $_{4}{ }^{*}$ & 0.72 & 0.43 & 0.55 & 0.60 & 0.79 & 0.56 & 1.39 & 0.95 \\
\hline Symm & 0.51 & 1.10 & 0.54 & 0.73 & 0.68 & 0.30 & 0.52 & 0.32 \\
\hline Ecce & 0.14 & 0.64 & 0.56 & -0.57 & 0.43 & -0.02 & 0.10 & 0.00 \\
\hline
\end{tabular}

Table 1: Mean values of the variables for the subjective database and for the 7 cyclone types. (*Units $\left.10^{-4} s^{-1}\right)$

Type 1 cyclones are weak for both gridlengths, asymmetric and eccentric in the E-W direction. They present a strong pressure gradient to the north (from the centre) and a very weak one to the east (from the centre). Type 1 is the less frequent one, $5.9 \%$ of the total. Its seasonal distribution shows a maximum in winter and a minimum in summer (31.5 and $17.2 \%$ of type 1 cyclones). Most of these cyclones are placed in the south of the Pyrenees. Due to the proximity of the cyclones to some main mountain ranges and to the strong cyclone pressure gradient along the direction where the mountain range is placed, this typology may consist of weak orographic cyclones.

Type 2 cyclones present weak geostrophic vorticity for both gridlengths and they are quasi-symmetric and eccentric in the E-W direction. The pressure gradient is similar to the north and to the south on one hand, and to the west and to the east in the other (around the double the north-south than the east-west gradients). This type represents the $18.6 \%$ of the total cyclones. It is quite spread in all seasons, with a maximum in autumn $(27.8 \%)$ and a minimum in spring $(21.7 \%)$. The cyclones of this typology are located, preferably, in the south of the Pyrenees, the Alboran Sea, the Algerian Sea and the Gulf of Genoa. As well as type 1, these cyclones could mainly be weak orographic cyclones.

Type 3 cyclones are weak for both gridlengths, asymmetric and eccentric in the N-S direction. The pressure structure is nearly the same as the for type 2, but rotated 90 anticlockwise. Type 3 represents the $11.1 \%$ of the total of cyclones. This type has a maximum of frequency in autumn (27.9\%) and a minimum in winter (18.3\%). The low centres are located in the south of the Pyrenees, the mainland and at the eastern coast of Spain, in the Gulf of Cádiz and in the Gulf of Genoa. They could be related to orographic influences (for mountain ranges oriented in the N-S direction), weak thermal lows and/or fronts which crosses the area (from west to east).

Type 4 cyclones present moderate geostrophic vorticity in $200 \mathrm{~km}$ and weak in $400 \mathrm{~km}$ gridlengths, asymmetry and are eccentric in the E-W direction. For these cyclones it must be pointed out the strong pressure gradient to the north and west (from the centre). This type represents the $13.4 \%$ of the total, with a maximum in spring and summer $(27.9 \%)$ and a minimum in autumn $(18.9 \%)$. Preferably, these cyclones are placed in the south of the Pyrenees but other areas with an important concentration of cyclones are the Gulf of Genoa and the Alboran Sea. As types 1 and 2, they could be orographic cyclones, but more intense than types 1 and 2.

Type 5 cyclones are weak in both gridlengths, symmetric and non-eccentric. The pressure gradient is the same in all the four directions (from the centre), so these cyclones have nearly circular shape. This type is the most frequent type $(24.9 \%$ of the total), with a maximum in summer $(29.4 \%)$ and a minimum in winter $(19.2 \%)$. Their centres are widespread in all the zones, standing out the Gulf of Genoa, the Tyrrhenian Sea and the south of the Pyrenees. 

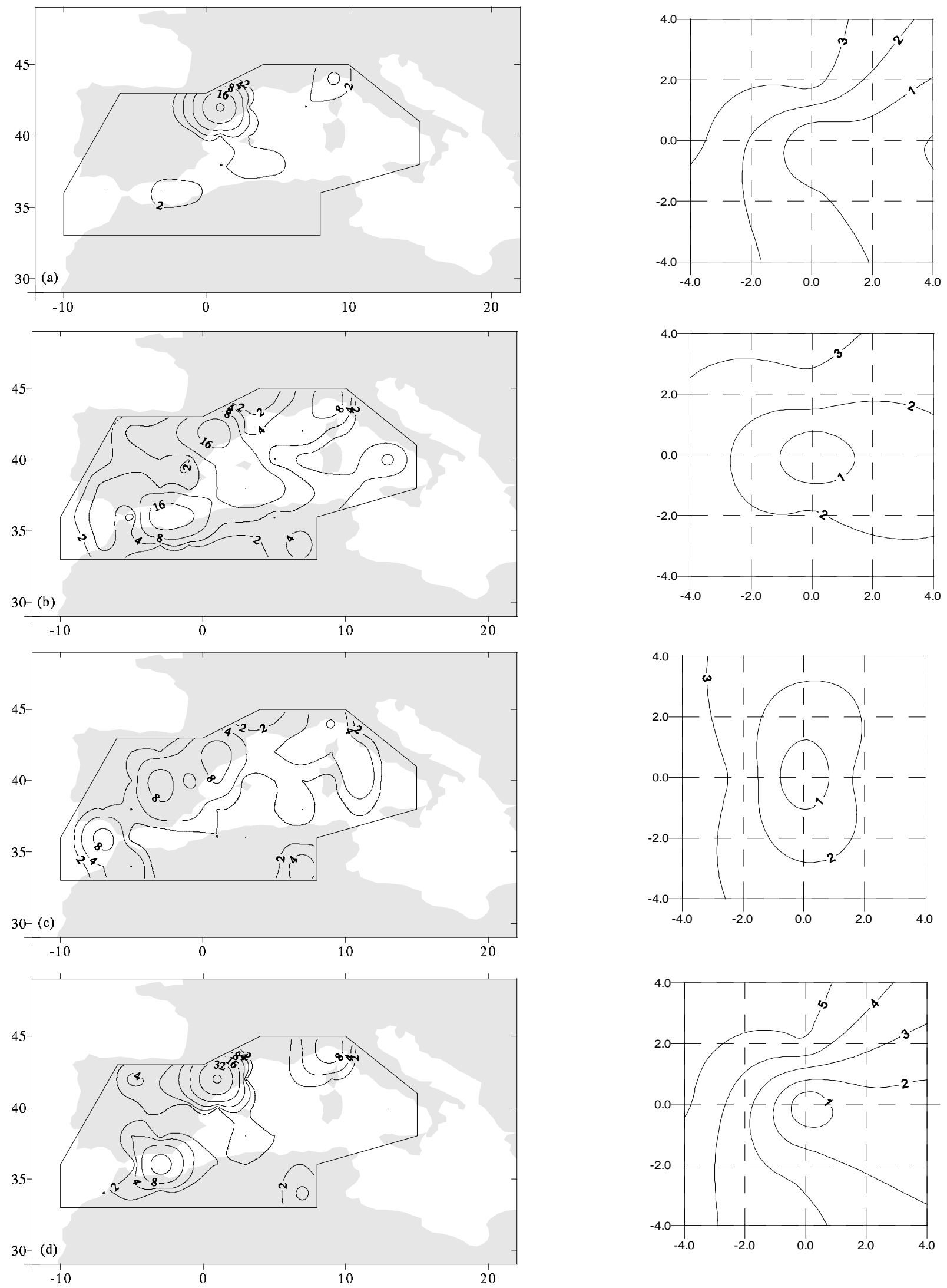

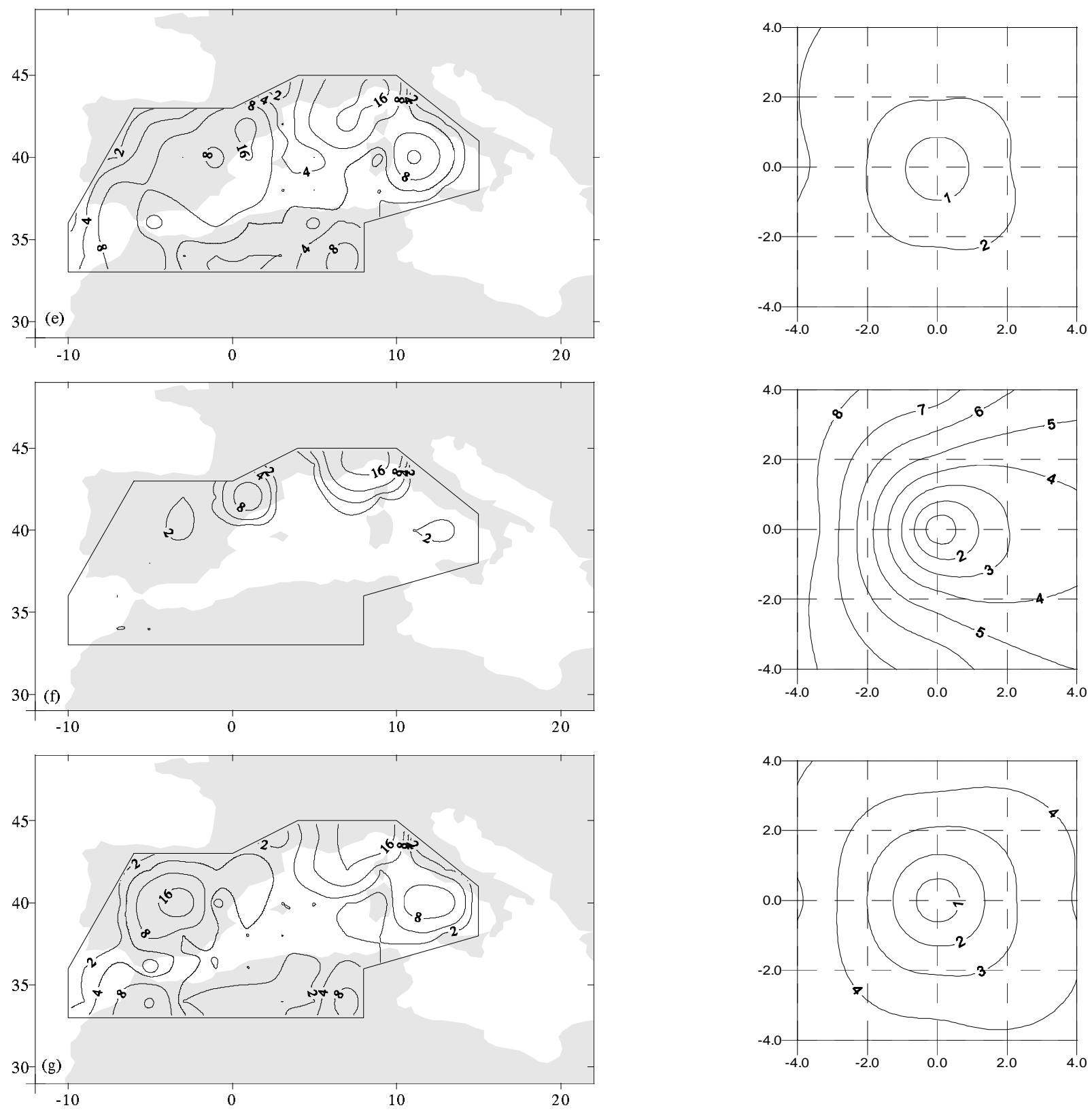

Figure 6: Left column as Figure 3a for the 7 typologies obtained from the cluster analysis on the subjective database. Contours of 2, 4, 8, 16, 32 and 64 cyclones per year are shown. Right column as Figure 3b for the 7 typologies obtained from the cluster analysis on the subjective database. Contour interval $1 \mathrm{hPa}$. (a) Type 1, (b) Type 2, (c) Type 3, (d) Type 4. Next page, (e) Type 5, (f) Type 6 and (g) Type 7. 
Type 6 cyclones present strong geostrophic vorticity in both gridlengths, quasi-symmetry and are non- eccentric. The pressure gradient is strong to the north, west (where it is up to $2 \mathrm{hPa} / 100 \mathrm{~km}$ ) and to the south and weaker to the east. This type is, together with type 1, the less frequent (6.7\% of the total). It presents a maximum in spring $(31.2 \%)$ and a minimum in autumn (14.5\%). The low centres are located, preferably, in the Gulf of Genoa and in the south of the Pyrenees. They could be intense orographic lows and well developed cyclones.

Type 7 cyclones are moderate in both gridlengths, symmetric and non-eccentric. The pressure distribution around the centre is regular in the four directions as in type 5, but stronger. This type is formed by the $19.4 \%$ of the total. It presents a maximum in summer $(39.1 \%)$ and a minimum in winter $(16.0 \%)$. They are placed, preferably, in the Gulf of Genoa and in the mainland Spain but also those placed in the Tyrrhenian Sea, the south of the Pyrenees, the eastern border of the Iberian Peninsula and Algeria and in Morocco must be pointed out. For this reason, the location of many of them on land, and the outstanding maximum in summer suggest that this typology is mainly composed by moderate thermal lows.

From another point of view it is interesting to establish if there is or not a dominant typology in each area of maximum concentration of cyclones. In the south of the Pyrenees the dominant types are 1,2 and 4. These types have a strong pressure gradient to the north (where the mountains are), what reinforces the possible orographic character of them. In the Gulf of Genoa, the most frequent types are 5, 6 and 7, but almost all types are frequent. Two types are dominant in the Alboran Sea: type 2 and type 4. Again it seems that the orography (the Iberian Peninsula to the north and the Atlas to the south) plays an important role in the presence of cyclones in that area. Types 3, 5 and 7 are the most frequent types in mainland Spain and in the Tyrrhenian Sea. In both areas it seems that the orography does not play an important role in the generation and shape of the cyclones (except for some of the lows of type 3). In the eastern edge of the Iberian Peninsula, the dominant typologies are 2, 3 and 5 . For those cyclones a certain orographic effect could be due to the Iberian Peninsula (for western component flow). The dominant typologies in the Gulf of Cádiz are 2, 3 and 5. Finally, in the Algerian Sea the most frequent type is 2 (more than $50 \%$ of the cases in that area), and again the possible influence of the Atlas mountains in the generation and shape of them is suggested.

\section{Objective cyclone database: catalogue and classification}

An objective cyclone climatology for a six-year period (1987-1992) was performed (Picornell et al., 1994) by using the old LAM-INM analyses at $1000 \mathrm{hPa}$ (at 00 and $12 \mathrm{GMT}$ ). The LAM-INM analysis was based on an Optimum Interpolation scheme (Díaz-Pabón, 1988). The horizontal resolution was 0.91 in latitude- longitude and it had 15 levels in the vertical. Due to the gridlength of the analysis (around $100 \mathrm{~km}$ ) only a few mesoscale cyclones were included. This catalogue was later extended until 1995 and so, in order to compare the catalogue of cyclones and a further classification of them with the subjective one, a sub- database was built. This new database was formed with all the cyclones included in a study area similar to the subjective one (from $33^{\circ}$ to $45^{\circ} \mathrm{N}$ and from $10^{\circ} \mathrm{W}$ to $16^{\circ} E$, see Figure 1) from the old LAM-INM, and for the same period of time (1992-1995).

The mean number of cyclones per year in the objective database in the study area is 946 (cyclones/year). Their location frequency shows a prominent maximum in the Gulf of Genoa. Secondary maxima are located at the northern and southern part of the Pyrenees, in the north-west and in the south-east of Spain, the Algerian Sea, the eastern border of the Iberian Peninsula, the Alboran Sea and Morocco (Figure 7). The seasonal distribution is similar as from the subjective catalogue, with a maximum in summer $(32 \%)$ and a minimum in winter (19\%). But again the presence of cyclones in each area shows a big dependence on the season. The Gulf of Genoa, the northern part of the Pyrenees, the north-west of Spain and the Algerian Sea present a maximum in summer and a minimum in winter. By the contrary, the southern part of the Pyrenees and the south-east of Spain present a maximum in winter and a minimum in summer. Finally the cyclones located in Morocco and the eastern border of the Iberian Peninsula are almost equally frequent during the whole year. In this case the thermal effect on the cyclone appearance was not so clear as it was in the subjective database.

In order to obtain a classification of cyclones from the objective database the next steps were followed. First of all for each cyclonic centre the $1000 \mathrm{hPa}$ geopotential values at the centre and at distances of 200 and $400 \mathrm{~km}$ from it were obtained (from the grid points and by a linear interpolation). Next the geostrophic vorticity was calculated from the values at 200 and $400 \mathrm{~km}$ as well as the symmetry and the eccentricity in the same way as defined in Section 4.1. Thus, the cluster analysis was performed in an identical way as for the subjective database, i.e. same method, number of typologies and seed points calculation. In Table 2 the mean value of the variables for the whole database and for the seven clusters obtained from the objective database are shown. In general the results from the 

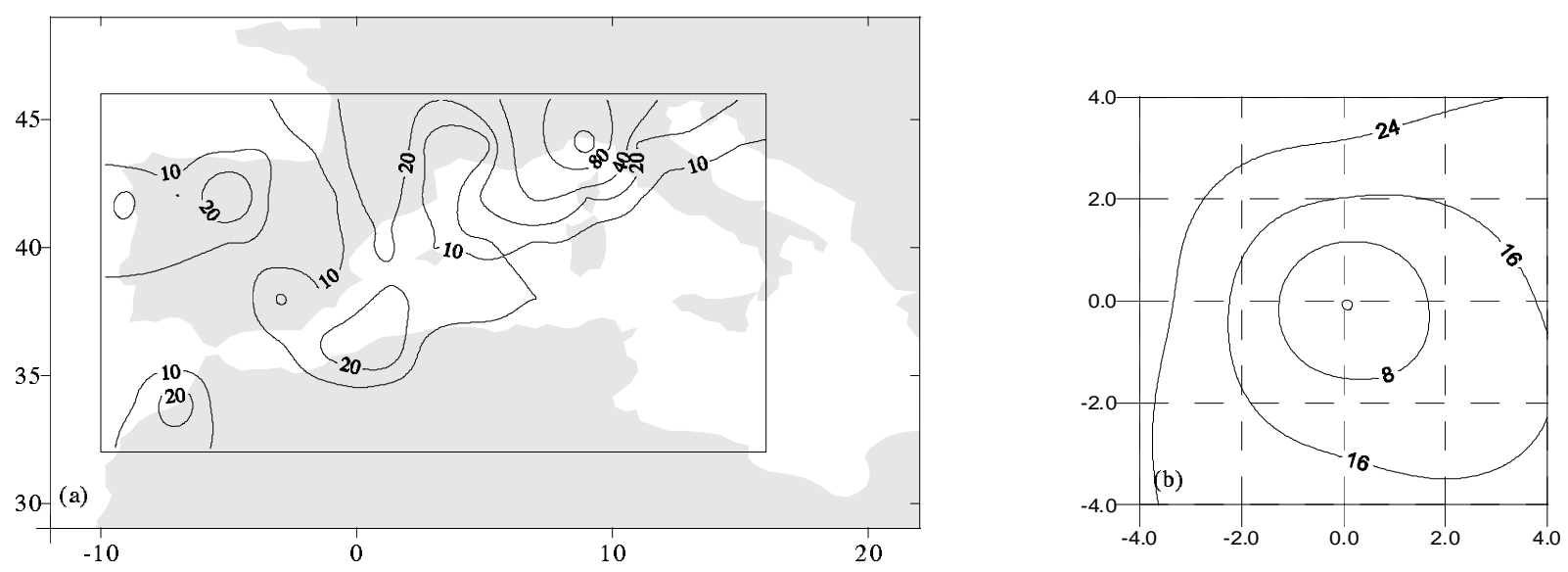

Figure 7: As Fig 3 for the objective cyclone database. (a) Contour interval 10, 20, 40, 80 and 120 cyclones per year. (b) Contour interval 8 geopotential metres.

cluster analysis for the objective cyclone database are quite similar to those obtained from the subjective cyclone database (compare Table 1 and Table 2). Therefore, instead of presenting the characteristics of all the typologies of the objective database, we prefer to comment the similarities and differences between both databases.

When comparing the results of both databases it must be taken into account the limitations of each cyclone detection method. In the subjective analysis the analyst uses some additional information as satellite imaginery and conceptual models. It makes possible the detection of mesoscale cyclones but it is impossible to avoid the subjectivity and so some biases are included into the database. The differences in data coverage will also introduce clear differences in the detectability of small cyclones from subjective analysis. On the contrary, the objective method avoids the subjectivity, but the limitations of the analysis and the gridlength impose some restrictions on the number and on the size of the cyclones that can be detected. A first comparison between the subjective and objective databases was performed for the period of summer and autumn of 1995 (Picornell et al., 1997). It revealed that the subjective method was better than the objective one because many of mesoscale cyclones were detected by hand-analysis but not by the LAM-INM analysis.

\begin{tabular}{|c|c|c|c|c|c|c|c|c|}
\hline & Database & Type 1 & Type 2 & Type 3 & Type 4 & Type 5 & Type 6 & Type 7 \\
\hline Vort $_{2}{ }^{*}$ & 1.33 & 1.07 & 1.11 & 1.10 & 1.74 & 1.11 & 2.81 & 1.76 \\
\hline Vort $_{4} *$ & 0.59 & 0.44 & 0.48 & 0.49 & 0.82 & 0.47 & 1.36 & 0.82 \\
\hline Symm & 0.62 & 1.04 & 0.60 & 0.82 & 0.76 & 0.38 & 0.47 & 0.40 \\
\hline Ecce & 0.13 & 0.62 & 0.47 & -0.37 & 0.24 & -0.05 & 0.09 & 0.00 \\
\hline
\end{tabular}

Table 2: Mean values of the variables for the objective database and for the 7 cyclone types. (*Units $\left.10^{-4} s^{-1}\right)$

The comparison between both databases reveals a much more number of cyclones detected with the subjective database than with the objective one (1609 versus 946 cyclones per year). But this difference is not geographically uniform. While in the Genoa-Liguria area the number of cyclones is nearly the same, in other areas with a high frequency of cyclones the number of cyclones in the subjective database is lower than in the objective one (i.e. in the south of the Pyrenees and in mainland Spain). It can be due to the low resolution of the objective database as regards the subjective one. The mean values of geostrophic vorticity are weaker for the objective database than for the subjective one, mainly the vorticity at $200 \mathrm{~km}\left(1.33 \mathrm{in}\right.$ front of $\left.2.0210^{-4} \mathrm{~s}^{-1}\right)$ and less at $400 \mathrm{~km}(0.59 \mathrm{in}$ front of $0.7210^{-4} s^{-1}$ ). On the contrary the two adimensional variables (the symmetry and the eccentricity) are similar for each databases. The pressure gradients for the objective database are similar to the subjective ones, and also the pressure distribution of the centroids are nearly the same (compare Figures $3 \mathrm{~b}$ and $7 \mathrm{~b}$ ). Concerning the seasonal distribution (not shown) it can be observed that some typologies have different seasonal distribution for each database (types 1, 2, 3 and 6) but the other (types 4,5 and 7) have the same. Also the spatial distribution presents important differences: most of the objective cyclones are placed in the Gulf of Genoa; for all types this 
area has the highest frequency (specially for type 7, with around 50\%). It is interesting to note the high frequency in the south of the Pyrenees for type 1, in the Alboran Sea and the Algerian Sea for type 2, the north of the Pyrenees, the east of the Iberian Peninsula and the Gulf of Cádiz for type 3, the Gulf of Cádiz for type 4 and finally the north of the Pyrenees and the Alboran Sea for type 5. Another difference between the obtained typologies of both databases is the percentage of elements of each type; the subjective database has a higher frequency of cyclones of types 4, 5, 6 and 7 and lower of types 1,2 and 3 .

\section{Conclusions and further remarks}

In this study, we have presented the characteristics of the surface cyclones of the Western Mediterranean by means of two different databases (based on subjective and objective analyses). Although the period of 4 years is too short for obtaining a climatology of cyclones, the present results are believed to give a useful description about the Mediterranean cyclones. From those data some conclusions can be stressed:

(i) The high number of cyclones in the Western Mediterranean when a subjective mesoscale analysis is performed. Although the inherent errors of the subjective cyclone database, the detected number of cyclones with this method is much higher than the detected cyclones with any synoptic or macroscale one (as the LAM-INM objective database or others).

(ii) The Western Mediterranean cyclones are not uniformly distributed. Therefore some areas with a high concentration of cyclones are found. The highest concentration of cyclones is located close to the mountain- ranges (the maxima are placed in the south of the Pyrenees and the Alps) and then their possible orographic origin is suggested. Other areas with a high concentration of cyclones as the Alboran Sea, mainland Spain and the Tyrrhenian Sea are also identified.

(iii) There exist differences in the seasonal frequency of the Western Mediterranean cyclones. Thus, in some areas the maximum is reached in summer and the minimum in winter (mainland Spain), while in others the distribution is the opposite (the Alboran Sea). In other areas (the south of the Pyrennees, the Gulf of Genoa and the Tyrrhenian Sea) the seasonal distribution is nearly uniform. In general, a tendency to locate the cyclones over land during the summer and over the sea in winter can be concluded.

Besides the catalogation of cyclones in the Western Mediterranean cyclones, a classification of both databases by means of a cluster analysis method was carried out. The classification was performed from the intensity of the cyclones and the shape of the pressure field. Seven typologies of cyclones in the Western Mediterranean are described. The results obtained from the two databases present similar mean values: spatial, seasonal and pressure distributions. For this reason, we can conclude that these seven groups represent real typologies of cyclones in the Western Mediterranean. Furthermore, it can be stated that:

(iv) Most of the Western Mediterranean cyclones are mesoscale, weak, asymmetric and eccentric in the E-W direction (types 1, 2 and 4) or symmetric and circular (types 5 and 7). Only a small part of them are weak, asymmetric and eccentric in the N-S direction (type 3) or strong, symmetric and circular (type 6). In general a clear relationship between typologies and cyclonic origin could not be stablished. Nevertheless, a trace of orographic (for types 1, 2, 3 and 4), thermal (for types 3 and 7) or baroclinic (for type 6) origin can be deduced.

Some of the differences between both databases can be explained from the different origin of them. It must be taken into account that the limitations of the analysis of the LAM-INM and its resolution impose some restrictions on the size of the structures that can be detected. So, due to the fact that the LAM-INM analysis smoothes the pressure structures, the manual analysis detects more cyclones than the objective one, especially in the south of the Pyrenees and in the Alboran Sea. Therefore the cyclones in those areas, and others, seem to be of small horizontal scale (mesoscale) and only can be detected with the subjective analysis or an objective mesoscale analysis. Besides, the centres detected by the objective analysis are less intense that it could be expected. Moreover, the subjective analysis is potentially the best analysis, but applied to a large amount of data presents some disadvantages. As it was explained before there are areas with lack of data and the subjectivity of the analyst introduces some biases but also it is hardly applied to long periods of time and large areas. On the contrary, the objective analysis would avoid most of the commented problems, but some restrictions are imposed by the analysis. Then, for the Western Mediterranean cyclones an objective analysis based on a mesoscale numerical model (with a gridlength of around $50 \mathrm{~km}$ or less) and a time interval of 6 hours is needed to perform cyclone and cyclogenesis climatologies.

The present work is a first attempt of characterisation of the Western Mediterranean cyclones. Due to the fact 
of using only sea-level pressure values, the obtained classification gives us an idea on the shape and strength of this field. But it is clear that a full description of cyclones requires other variables as the temperature, humidity, wind, as well as the distribution of these variables at different levels in the vertical. That is a tridimensional characterisation of the cyclones. It implies a hard work that can be only carried out with an objective method. Then a more complete catalogue would be available, and also a classification of cyclones based on this catalogue could be performed. This work is at the moment at an initial stage, and some variables have been chosen in order to describe tridimensionally the cyclones. The used analysis is the HIRLAM-INM, with a horizontal resolution of $0.5^{\circ}$ latitude-longitude. In the vertical seven pressure levels (from the earth surface to $300 \mathrm{hPa}$ ) are selected.

\section{Acknowledgements}

This work has been partially supported by the CICYT CLI95-1780 grant. 


\section{References}

Alpert, P., B.U. Neeman and Y. Shay-El, 1990: Climatological analysis of Mediterranean cyclones using ECMWF data. Tellus 42A, 65-77.

Andenberg, M.R., 1973: Cluster Analysis for applications. Academic Press, New York, 359 pp.

Bessemoulin, P., P. Bougeault, A. Genovés, A. Jansà and D. Puech, 1993: Mountain pressure drag during PYREX. Beitr. Phys. Atmosph. 66, 305-325.

Bougeault, P., A. Jansà, B.Benech, B. Carissimo, J. Pelon and E. Richard, 1990: Momentum budget over the Pyrnes: The PYREX experiment. Bull. Am. Meteorol. Soc. 71, 806-818.

Campins, J., A. Jansà, B. Benech, E. Koffi and P. Bessemoulin, 1995: PYREX Observation and Model Diagnosis of the Tramontane Wind. Meteorol. Atmos. Phys. 56, 209-228.

Díaz-Pabón, R., 1988: Modelo operativo en el INM de analisis tridimensional de campos meteorolgicos. Serie A n 135, Instituto Nacional de Meteorología, Madrid, 71pp.

Genovés, A. and A. Jansà, 1989: Statistical approach to mesoscale non-alpine West Mediterranean cyclogenesis. WMO/TP n 298, 77-85.

Genovés, A., A. Jansà and C. Estarellas, 1997: First Evaluation of Orographic Factor in Western Mediterranean Cyclogenesis, in INM/WMO International Symposium on Cyclones and Hazardous Weather in the Mediterranean, MMA-INM, UIB, Palma, 273-282.

Gong, X. and M.B. Richman, 1995: On the applications of Cluster Analysis to growing season precipitation data in North America East of Rockies. J. Climate 8, 897-931.

H.M.S.O., Meteorological Office, 1962: Weather in the Mediterranean, PUB. 391, Vol.1, General Meteorology, London, $362 \mathrm{pp}$.

INM (A. Genovés coord.) 1992, 1993, 1994, 1995, 1996 and 1998: Boletín PEMMOC n 1, 2, 3, 4, 5 y 6. Instituto Nacional de Meteorología, Madrid.

Jansà, A., A. Genovés, R. Riosalido and O. Carretero, 1996: Mesoscale cyclones vs. heavy-rain and MCS in the Western Mediterranean. MAP Newsletter, n 5, Switzerland, 24-25.

Jansà, A., A. Genovés, M.A. Picornell, J. Campins, R. Riosalido and O. Carretero, 1999: Western Mediterranean cyclones and heavy rain. Part 2: Statistical approach. Met. Apps. (accepted).

Petterssen, S., 1956: Weather Analysis and Forecasting. Vol. I. Mac Graw Hill, New York, 428 pp.

Picornell, M.A. M.C. Martín and A. Jansà, 1994: INM-LAM Catalogue of Mediterranean Cyclones. WMO PWPR Rep. Series, n 4 (WMO/TD 600), App 3, 24-33.

Picornell, M.A., A. Genovés and A. Jansà, 1997: Mesocyclones detectability by using objective analysis, in INM/WMO International Symposium on Cyclones and Hazardous Weather in the Mediterranean, MMA- INM, UIB, Palma, 55-62.

Radinovic, D. and D. Lalic, 1959: Cyclonic activity in the West Mediterranean. Federal Hydromet. Institute. Memories num 7, Belgrade, 57 pp.

Radinovic, D., 1978: Numerical model requirement for the Mediterranean area. Riv. Meteor. Aeron. 38, 191- 205.

Radinovic, D., 1987: Mediterranean cyclones and their influence on the weather and the climate. WMO, PSMP Rep. Ser. num 24.

Reiter, E., 1975: Handbook for forecasters in the Mediterranean: Weather phenomena of the Mediterranean basin. Naval Environmental Prediction Research Facility Master, Tech. Pap. 5/75, Monterey, 344 pp. 